\title{
Thyrotoxic periodic paralysis
}

INSERM

\section{Source}

INSERM. (1999). Orphanet: an online rare disease and orphan drug data base. Thyrotoxic periodic paralysis. ORPHA:79102

Thyrotoxic periodic paralysis (TPP) is a rare neurological disease characterized by recurrent episodes of paralysis and hypokalemia during a thyrotoxic state. 